\title{
Cost-Benefit Analysis and Emission Reduction of Energy Efficient Lighting at the Universiti Tenaga Nasional
}

\author{
G. S. B. Ganandran, ${ }^{1}$ T. M. I. Mahlia, ${ }^{1,2}$ Hwai Chyuan Ong, \\ B. Rismanchi, ${ }^{3}$ and W. T. Chong ${ }^{3}$ \\ ${ }^{1}$ Department of Mechanical Engineering, Universiti Tenaga National, 43000 Kajang, Selangor, Malaysia \\ ${ }^{2}$ Department of Mechanical Engineering, Syiah Kuala University, Banda Aceh 23111, Indonesia \\ ${ }^{3}$ Department of Mechanical Engineering, Faculty of Engineering, University of Malaya, 50603 Kuala Lumpur, Malaysia
}

Correspondence should be addressed to Hwai Chyuan Ong; onghc@um.edu.my

Received 22 April 2014; Accepted 15 June 2014; Published 15 July 2014

Academic Editor: Hua Bai

Copyright (C) 2014 G. S. B. Ganandran et al. This is an open access article distributed under the Creative Commons Attribution License, which permits unrestricted use, distribution, and reproduction in any medium, provided the original work is properly cited.

This paper reports the result of an investigation on the potential energy saving of the lighting systems at selected buildings of the Universiti Tenaga Nasional. The scope of this project includes evaluation of the lighting system in the Library, Admin Building, College of Engineering, College of Information Technology, Apartments, and COE Food court of the university. The main objectives of this project are to design the proper retrofit scenario and to calculate the potential electricity saving, the payback period, and the potential environmental benefits. In this survey the policy for retrofitting the old lighting system with the new energy saving LEDs starts with $10 \%$ for the first year and continues constantly for 10 years until all the lighting systems have been replaced. The result of the life cycle analysis reveals that after four years, the selected buildings will bring profit for the investment.

\section{Introduction}

In order to ensure a comfort, safe, and productive environment, the lighting system must provide suitable condition with desired illumination level. At the same time, lighting system needs to be designed in such a way that consumes the optimum amount of energy. In this modernized era, light source can produce the equal light compared with the traditional lighting systems used 20 years ago, while consuming half the energy input. Malaysia as a fast developing country has to look forward to energy efficiency technologies due to several factors such as cost increment in building new power plants, continuing shortfall between electricity demand and supply, and competing needs for investment capital.

Among all the electric consumers, lighting has one of the highest shares in the residential and commercial sector. Lighting accounts for approximately $20 \%$ to $30 \%$ of the electricity consumption worldwide $[1,2]$. By switching towards more energy efficient lighting technologies, a considerable amount of energy could be saved [3]. The study by Trifunovic et al. [4] showed a potential energy saving of up to $27 \%$ in residential and $30 \%$ in the commercial sector.

The process of replacing inefficient light systems with more advanced and high efficiency systems are called lighting retrofits. The success of a retrofit program depends on different parameters, such as policies and regulations, occupant's expectation, building specification, and human factors, which has the highest effect among other parameters [5]. These parameters are highly interdependent and could have a significant impact on the design.

The increase in energy consumption contributes significantly to the environment in consequences of the emission production. Almost $80 \%$ of the world electricity is produced from the combustion of fossil fuels. This eventually has changed the pattern of emission production. The gases that are being produced by burning the fossil fuels are "greenhouse gases" which contributes to global warming, ozone depletion, acid rain, and other negative impacts [3]. 
1.1. Incandescent Light Bulbs. Incandescent light bulbs have been the most commonly used light sources over the past one and a half decade also called the "Edison Bulb." They have a simple technology; when connected to a power supply, the electric current heated the wires and tungsten filament to 4,000 degrees Fahrenheit and tungsten begins to evaporate. Without the inert gasses (argon and nitrogen), the tungsten particles would collect on the inside of the glass, causing it to darken. The gasses, however, collect the tungsten particles and send them back to the filament. However, almost $90 \%$ of the energy generated by an incandescent bulb is released as heat, not light.

1.2. Compact Fluorescent CFL. In the past few years, incandescent bulb starts to give way to more efficient fluorescent (FL), compact fluorescent (CFL), and light emitting diode (LED) lighting systems. CFL bulbs are one of the most successful innovations in the lighting industry; the modern CFL bulbs last 10 times longer than traditional incandescent bulbs. They consume far less energy to produce the same amount of light. For instance, a 15-watt CFL lamp emits the same amount of light as 60-watt incandescent bulb. Despite the great advantages of CFLs they have some limitations. Some CFLs do not perform well in low temperatures; it is possible for a CFL to produce radio frequency interference (RFI); they are not resistant to internal shock, and they have mercury within their glass cover. Many commercial and industrial facilities have old-fashioned inefficient FL lighting systems such as T-12 FL [6].

1.3. LED. The LED is what is called a "solid-state lighting" technology, or SSL. Basically, instead of emitting light from a vacuum or a gas, a SSL emits light from a piece of semiconductor made of a positively charged and a negatively charged component. The light is emitted when electrons move around within the semiconductor structure from the negative to the positive layer. In the early LED models, the structure of the LED causes some of that light to get trapped inside. Therefore, the old models are generally dimmer than an incandescent bulb. However, this problem has been solved in the new models and LED bulbs have brightened up. Many researches are in progress to optimize the performance and light quality of the LED bulbs and at the same time reduce their price [7-9]. There are basically 2 types of LEDs: the $5 \mathrm{~mm}$ LED chips and the high-output chip on board (COB). The $5 \mathrm{~mm}$ LED has low light output and lacks proper thermal path that is essential for maintaining the LED's junction temperature. Normally the luminous of the $5 \mathrm{~mm}$ LED would reduce to half of its original value after 6000 hours. The COB is known as the current choice for lighting since it offers far superior luminous output as well as having proper thermal path for regulating the LED's junction temperature. Figure 1 shows the Incandescent, CFL, and LED light bulbs.

Several studies have been conducted on the benefits of retrofitting conventional lighting systems with the new low energy ones $[10,11]$. Light emitting diode (LED) lamps are more effective than incandescent and CFL bulbs and have a longer lifetime while providing similar luminous. Uddin et al. [12] found that LED lamps are more expedient than conventional bulbs and also advance in terms of environment friendly but economical wise LEDs have higher initial costs. Chen and Chung [13] have studied retrofitting LEDs with T8 fluorescent tubes; they found that by replacing $36 \mathrm{~W}$ T8 fluorescent lamp with $20 \mathrm{~W}$ LED, would have around $\$ 288$ saving in 5 year operation.

Ryckaert et al. [14] conduct a research on the ups and downs of retrofitting LED tubes with T8 FL lamps. They analyse twelve different LED tubes and the results show that a one-to-one lamp replacement could lead to an inadequate quantity and quality of illumination of the work plane. In order to address this issue, additional LEDs are required which consequently would decrease the potential energy savings. In another study, Stefano [11] identified three main barriers to the cost effective installation of energy efficient lighting technologies in offices such as low lighting system operating hours, low cost of electricity, and high initial expense of energy efficient lighting components. Vahl et al. [15] analyse the long term sustainability of retrofitting inefficient light bulbs with CFLs and LEDs. They found that generally CFLs have the highest annual cost and toxic waste; FL tubes are the most economical alternative, but if their lifespans shorten and LED prices drop or achieve higher efficiency, LED becomes the most sustainable and economically alternative.

Mahlia [16] shows the method to calculate the potential emission from the fuel mix used by Malaysia to generate electricity. The author uses the polynomial equation to predict the energy consumption and the emission produced in the years 2002 to 2020 . The data of per unit of $\mathrm{CO}_{2}, \mathrm{SO}_{2}$, $\mathrm{NO}_{x}$, and $\mathrm{CO}$ emitted for electricity generation was obtained. Another study shows the prediction in a reduction on the amount of $\mathrm{CO}_{2}$ and $\mathrm{SO}_{2}$ emission in the years 2010, 2020, and 2050 by using biogas energy compared to traditional method [17].

In Malaysia, around $40 \%$ of greenhouse gases are contributed by residential buildings [18]. Therefore, it is necessary to reconstruct or retrofit the current buildings according to the green building valuation. In this project, the current lighting systems used at the Universiti Tenaga Nasional have been considered in which most of the current lamps are CFL two pin bulbs and fluorescence tubes. The current lighting system consumes considerable amount of energy to provide required light. The main objectives of this project are to design the proper retrofit and to calculate the potential electricity saving and the payback period for returning the investment. Also the potential environmental benefits have been analyzed as one of the key objectives of the project.

\section{Methodology}

The scope of this project includes evaluation of the lighting system in the Library, Admin Building, College of Engineering, College of Information Technology, Apartments, and COE Food court of the university. The calculation of the energy consumption is based on the wattage input consumed 

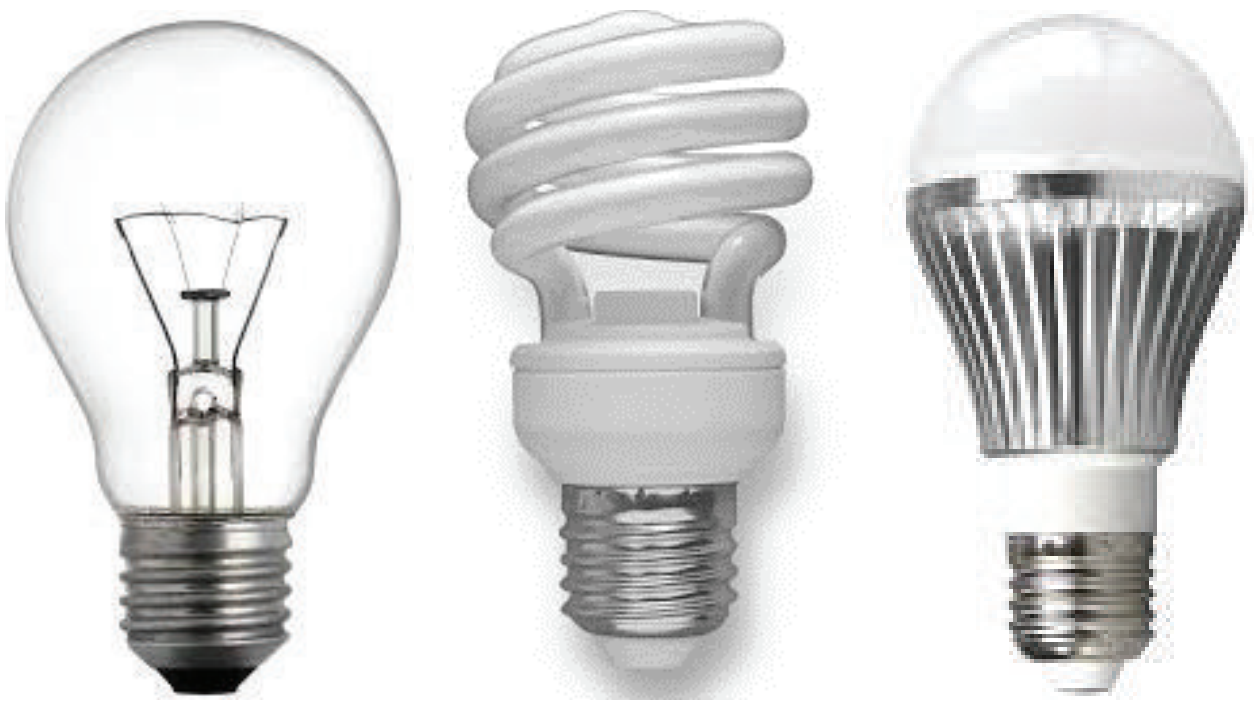

FIGURE 1: Incandescent, CFL, and LED light bulbs.

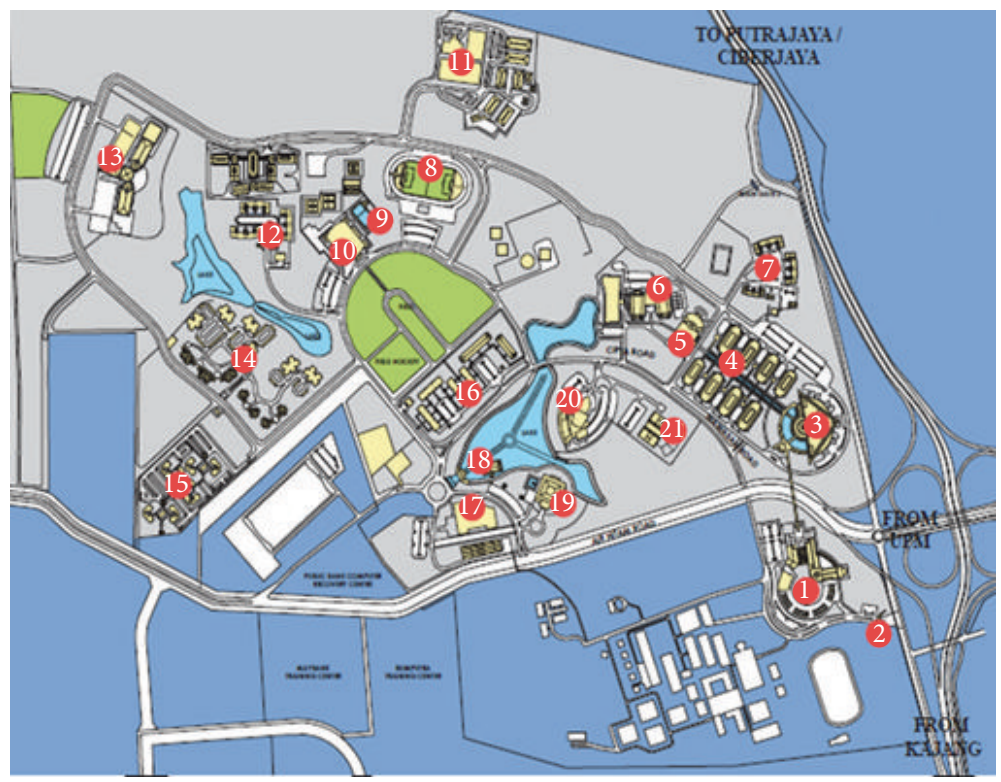

Figure 2: Map of Universiti Tenaga Nasional. (1) Library, (2) Main Gate, (3) Administration Building, (4) Laboratory and Training Block, (5) COE Food court, (6) College of Engineering, (7) Murni Apartment, (8) Mini Stadium, (9) Multipurpose Hall, (10) TNB Equestrian Centre, (11) Cendekiawan Apartment, (12) College of Information Technology, (13) Staff Quarters, (14) Amanah Apartment, (15) Ilmu Apartment, (16) Food court 1, (17) Lake Café, (18) Mosque, (19) Residence Hotel, and (20) Twin Tutorial Hall.

by light bulbs. Figure 2 shows the location of each building in the compound.

The number and type of lighting bulbs were counted manually during a walk-through audit; also the results were double checked with the lighting layout to minimize the data gathering error. The lighting layout was obtained from Facility Development \& Management Department and it shows the location and type of light used in each building in details. It has been identified that the most commonly used light bulbs are; Philips compact fluorescent light (CFL) $14 \mathrm{~W}$ fitting E27, Philips 36 W/4 Pin fitting 2G11, Philips PL-C 13 W
2 pin fitting G24, and Philips fluorescent tube $36 \mathrm{~W}$ for 4 feet and $18 \mathrm{~W}$ for 2 feet. Some of light bulbs are shown in Figure 3.

The Philips liner fluorescent tubes consume $36 \mathrm{~W}$ for the 4 feet long linear tube. They have approximately 15000 hours life time and produce 2250 lumens. The $18 \mathrm{~W}$ Philips fluorescent tube has lifetime of 15000 hours and produces 1350 lumens. The Philips CFL $14 \mathrm{~W}$ bulb comes with E27 fitting. This bulb produces approximately 800 lumens and has life time of 8000 hours. This kind of bulb was used as down light where the light is concentrated in downward direction. The Philips $36 \mathrm{~W} / 4$ pin with fitting 2 G11 is made 


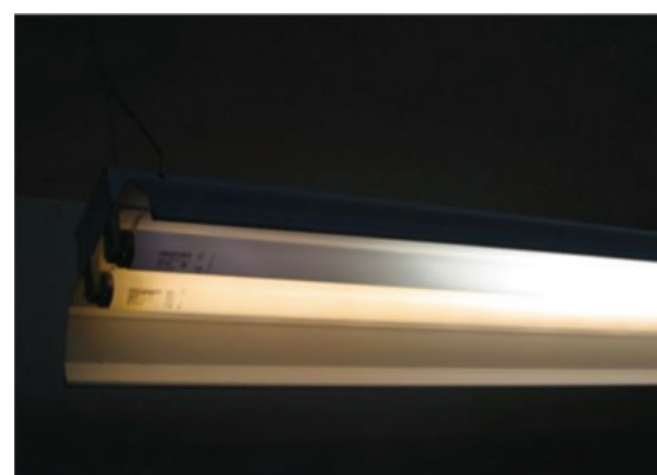

(a)

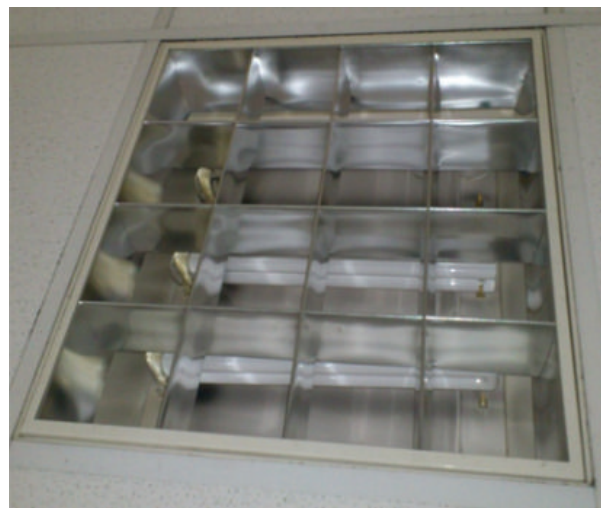

(c)

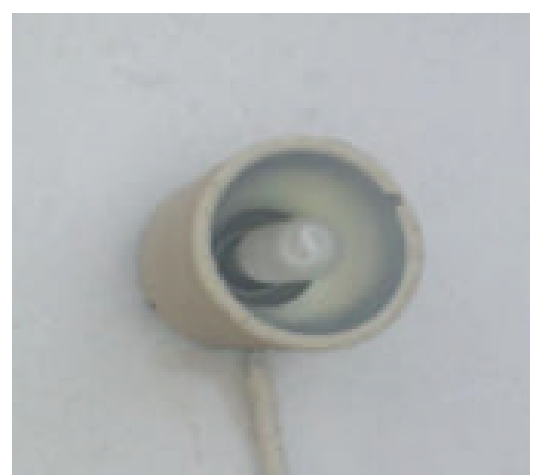

(b)

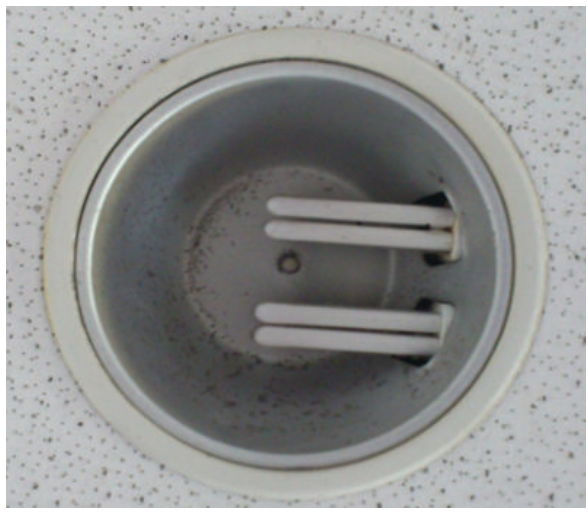

(d)

Figure 3: (a) Philips fluorescent tube 36 W 4 feet, (b) Philips compact fluorescent light (CFL) bulb 14 W fitting E27, (c) Philips 36 W/4 Pin fitting 2G11, and (d) Philips PL-C 13 W 2 Pin fitting G24.

up of compact fluorescent tube. Around the campus this kind of tube is commonly used to light up the buildings. These kinds of bulbs can produce up to 2000 lumens and have a life time up to 15,000 hours. The Philips PL-C 13 W 2 Pin fitting G24 produces up to 750 lumens and has life span hours up to 10,000 hours. Use of this bulb is for down lights application. 2 pin designed for easy setting up by just plug and pull.

2.1. Ideal Lighting Technology. The fluorescent tube and CFL are the main lighting systems in the campus. However, compared to the new technologies, they are not considered as energy efficient. The proper lighting technology that can be implemented is the LEDs. LEDs use $80 \%$ less energy than incandescent and $30 \%$ to $40 \%$ than most fluorescent lamps. LEDs are environmental friendly where they are mercury free, but fluorescent and CFL contain mercury and required special disposal or recycle method, which contribute to hazardous waste. LED sources have longer lifespans than traditional technologies which can save costs on replacement and maintenance. LEDs offer illumination without emitting harmful infrared or ultraviolet radiation.

In current market variable LED tubes are available which offer light output levels similar to $36 \mathrm{~W}$ fluorescent tubes. By substituting a $36 \mathrm{~W}$ T8 fluorescent tube by a $19 \mathrm{~W}$ LED tube can save up to $48 \%$. The wattage and cost of LED tubes to replace $36 \mathrm{~W}$ T8s varies according to manufacturers. The advantages of replacing LED tubes are that they are designed to fit directly into current fluorescent fitting by just removing and replacing the starter. LEDs cost higher than T8 to T5 converters but LED tubes have a significantly extensive lifespan of almost five times more dependent on the quality. The types of light chosen to replace the current lighting system are shown in Figure 4 . The light retrofitting has been recognized as one of the most effective methods of reducing overall energy consumption as suggested in the ISO50001:2011 standard and recommended practice under the ASEAN Energy Management Scheme (AEMAS). The light bulb selection in this study has been followed by the above mentioned standards to ensure supplying required lighting for staff and students in the selected buildings.

The 4 feet LED tube which consists of 192 LED produces $2100 \pm 100$ lumens with 50,000 hours lifetime. Efficiency can reach up to $90 \mathrm{~lm} / \mathrm{W}$. LED tube has an easy installing method by just removing the current tube including the ballast and simple rewiring which is suggested to be done by qualified electrician. The 2 feet LED tube which is made of 108 LED creates $1150 \pm 100$ lumens with 50,000 hours life span. The installation method is same as the 4 feet LED tube. The $22 \mathrm{~W} / 4$ pin LED tube is made up of 48 pieces SMD5630 LED and produces $1870 \pm 100$ lumens and also has 50,000 hours lifetime. This tube has a built in driver; therefore, 


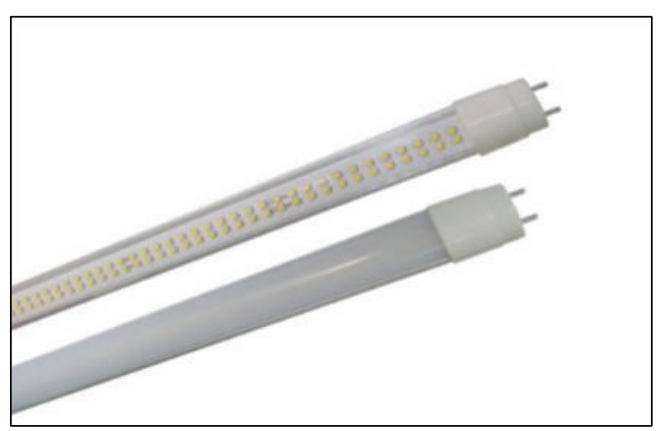

(a)

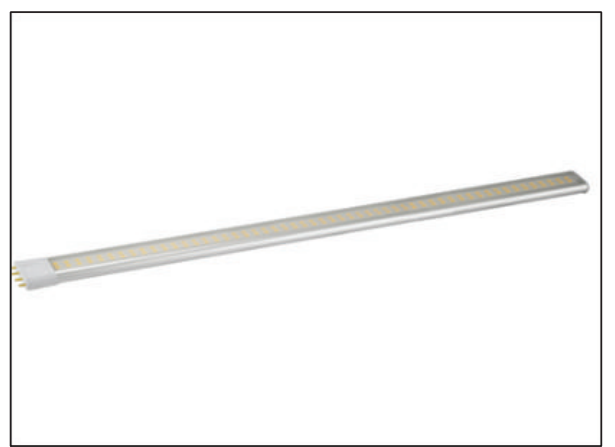

(c)

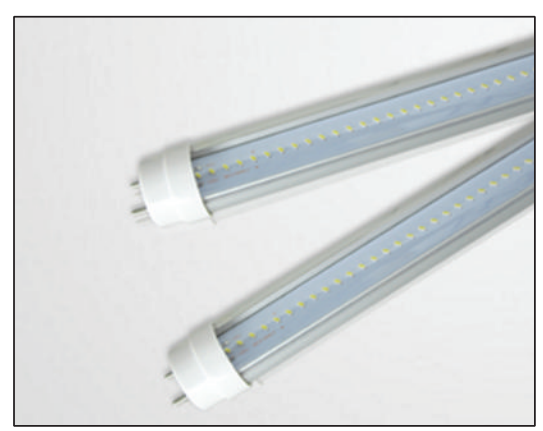

(b)

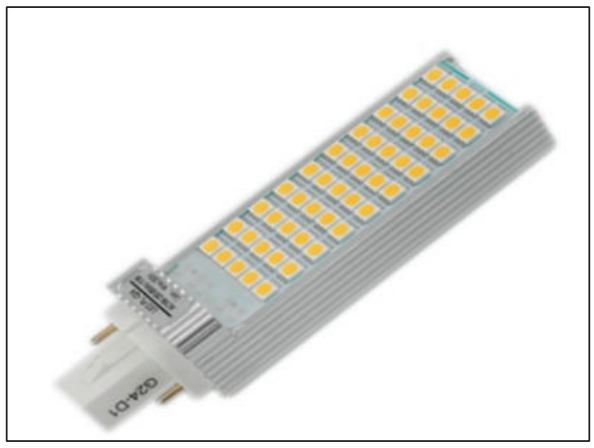

(d)

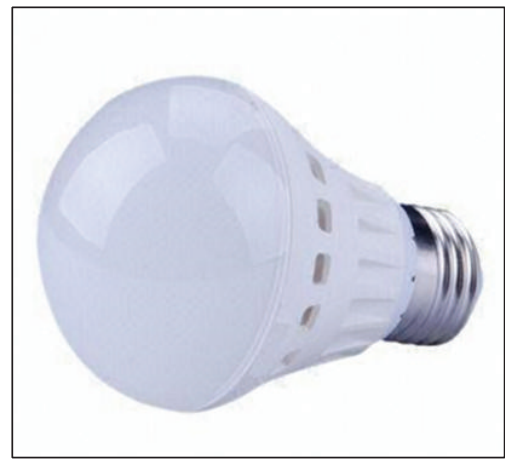

(e)

FIGURE 4: (a) $20 \mathrm{~W} 4$ feet LED tube replacing $36 \mathrm{~W}$ fluorescent tube, (b) $10 \mathrm{~W} 2$ feet LED tube replacing $18 \mathrm{~W}$ fluorescent tube, (c) $22 \mathrm{~W} / 4$ pin LED tube replacing Philips $36 \mathrm{~W} / 4$ Pin, (d) 8 W/2 pin LED replacing Philips PL-C 13 W/2 pin, and (e) 9 W LED bulb light replacing Philips $14 \mathrm{~W}$ (CFL) bulb.

the installation only require removing the electronic ballast of the existing lighting system. The $8 \mathrm{~W} / 2$ pin LED is made of 18 pieces SMD5630 LED and produces $650 \pm 80$ lumens. This LED light has 50,000 hours lifespan and built in driver. Last but not least, the $9 \mathrm{~W}$ LED bulb gives an equivalent output of a $14 \mathrm{~W}$ CFL. The lumens output is $650 \pm 70$ lumens and has 30,000 hours lifespan.

2.2. Potential Energy Saving. The total daily energy consumption (EC) is calculated by multiplying the total number of lamps $(\mathrm{N})$, power consumed by the lamp $(\mathrm{W})$, and total hours of operation $(\mathrm{OH})$, which is assumed 8 hours. The formula is interpreted in the following equation [10]:

$$
\mathrm{EC}=\frac{(\mathrm{N} \times \mathrm{W} \times \mathrm{OH})}{1000} .
$$

Total energy saving (ES) would be the difference between energy consumption of current system $\left(\mathrm{EC}_{\text {Current }}\right)$ and the retrofit lighting $\left(\mathrm{EC}_{\text {Retrofiting }}\right)$ system:

$$
\mathrm{ES}=\mathrm{EC}_{\text {Current }}-\mathrm{EC}_{\text {Retrofiting }} .
$$

Bill saving (BS) is calculated by the product of energy saving (ES) with electricity tariff (ET). In this case study 
TABLE 1: Emission factors ( $\mathrm{kg} / \mathrm{kWh}$ ) used for estimating emission in power plants.

\begin{tabular}{lcrrr}
\hline Fuel type & $\mathrm{CO}_{2}$ & $\mathrm{NO}_{x}$ & $\begin{array}{c}\mathrm{SO}_{2} \\
\mathrm{Kg} / \mathrm{kWh}\end{array}$ & $\mathrm{CO}$ \\
\hline Coal & 1.18 & 0.0052 & 0.0139 & 0.0002 \\
Natural gas & 0.53 & 0.0009 & 0.0005 & 0.0005 \\
Fuel oil & 0.85 & 0.0025 & 0.0164 & 0.0002 \\
Diesel & 0.85 & 0.0025 & 0.0164 & 0.0002 \\
\hline
\end{tabular}

TABLE 2: The amount of $\mathrm{CO}_{2}, \mathrm{SO}_{2}, \mathrm{NO}_{x}$, and $\mathrm{CO}$ emission production per $\mathrm{kWh}$ of electricity generation.

\begin{tabular}{lcccc}
\hline \multirow{2}{*}{ Fuels } & \multicolumn{4}{c}{ Emission $(\mathrm{kg} / \mathrm{kWh})$} \\
& $\mathrm{CO}_{2}$ & $\mathrm{SO}_{2}$ & $\mathrm{NO}_{x}$ & $\mathrm{CO}$ \\
\hline Coal & 1.1800 & 0.0139 & 0.0052 & 0.0002 \\
Petroleum & 0.8500 & 0.0164 & 0.0025 & 0.0002 \\
Gas & 0.5300 & 0.0005 & 0.0009 & 0.0005 \\
\hline
\end{tabular}

the electricity tariff is presumed to be increased about $2 \%$ every year. Consider

$$
\mathrm{BS}=\mathrm{ES} \times \mathrm{ET} .
$$

2.3. Payback Period and Life Cycle Cost Analysis. Payback period (PAY) is the time taken to obtain return of the money that has been invested. In this calculation the present value money is not taken into account during the calculation. Consider

$$
\mathrm{PAY}=-\frac{\Delta \mathrm{PC}}{\Delta \mathrm{OC}}
$$

Life cost analysis (LCC) is the total expenses involved during its lifespan. A standard calculation method for LCC is by summation of failure cost, maintenance cost which is known as the investment cost (PC), and the yearly operation cost $(\mathrm{OC})$ as presented in the following:

$$
\mathrm{LCC}=\mathrm{PC}+(\mathrm{PWF}) \times(\mathrm{OC}) .
$$

2.4. Decrement in Emission. Carbon and Hydrogen are considered as the main constituent of most fuels, followed by a small portion of sulphur. Combustion involves an oxidation reaction, in which the necessary oxygen is usually provided by air, a mixture of oxygen, and nitrogen [19-21]. In Malaysia, natural gas is used as the main fuel for power generation [22]. The emission production (EM) is equal to emission factor (EF) multiplied by the amount of fuel consumed (FC). Therefore, the emission $(p)$ due to using fuel $(f)$ in the year $(n)$ can be calculated with the following [23]:

$$
\mathrm{EM}_{n f}^{p}=\mathrm{EF}_{f}^{p} \times \mathrm{FC}_{n f} .
$$

The potential emission production of each fuel based on Malaysian condition is summarized in Table 1 [24].

The predicted amount of emission produced in the process of generating electricity in the years 2014 to 2024 was obtained from the predicted scenarios reported based on local condition [16]. The scenarios are tools for ordering perceptions about alternative future environments, and the result might not be an accurate picture of tomorrow but may give a better decision about the future for policy makers. Regardless of how things can actually be, both the analyst and the decision maker will have a scenario that resembles a given future and will help researchers consider both possibilities and consequences of the future $[25,26]$. The result is presented in Table 2 .

\section{Results and Discussion}

3.1. Lighting Audit. The result of the walk-through lighting audit in the above mentioned selected buildings is presented in Table 3. There are five common types of lighting system used in the selected buildings, which are fluorescent tube $36 \mathrm{~W}$ and $18 \mathrm{~W}$, Compact Fluorescent Light (CFL) $14 \mathrm{~W}$, CFL 4 pin $36 \mathrm{~W}$, and CFL 2 pin $13 \mathrm{~W}$. The most commonly used bulb is the Philips $36 \mathrm{~W} / 4$ Pin with 2 G11 fitting that makes the total number of 28431 bulbs. There are 8751 of $36 \mathrm{~W}$ fluorescents 4 feet tube and 12674 of $18 \mathrm{~W}$ fluorescent 2 feet tube. The quantity of Philips PL-C 13 W/2 Pin and Philips CFL bulb $14 \mathrm{~W}$ are 12719 and 109, respectively. The total number of lamp used in the selected buildings is 62684 .

The interview with the staff reveals that in the selected buildings the normal working hours of the lighting system are 8 hours a day, 5 days a week. However, there are always some exceptions due to unscheduled working hours or safety issues.

3.2. Energy Consumption. Based on the latest electric tariff rate by the TNB, the national electricity provider, the tariff rate for the low voltage commercial building is RM0.393 per $\mathrm{kWh}$. It was assumed that the electric tariff will have around $2 \%$ increase each year [27]. In this survey the policy for retrofitting the old lighting system with the new energy saving LEDs starts with $10 \%$ for the first year and continues constantly for 10 years until all the lighting systems have been replaced.

The result for total energy consumption of the existing lighting system is presented in Table 4 . The total electricity consumption for the lighting application of the selected buildings is around $13,868.46 \mathrm{kWh}$ per day. Meanwhile, the total consumption of electricity per day for the LED light would be around $8,239.8 \mathrm{kWh}$ that shows the potential $40.59 \%$ saving.

Consequently around $1,463,450.56 \mathrm{kWh}$ of energy and RM 517,622 of the bill can be saved each year, if all the existing lighting systems have been replaced with the energy saving LEDs. Table 5 presents the energy consumption of the proposed LED system in 10 years. It is shown that by increasing the percentage of the retrofitted lighting systems the overall energy consumption decreased. In 2024, when full retrofitting has been achieved the energy consumption will remain constant if the duration of usage of light is supposed constant. 
TABLE 3: Number of light collected for each building.

\begin{tabular}{|c|c|c|c|c|c|}
\hline \multirow{2}{*}{ Buildings } & \multicolumn{5}{|c|}{ Types of light used } \\
\hline & Fluorescent tube $36 \mathrm{~W} 4$ feet & CFL $14 \mathrm{~W}$ & $13 \mathrm{~W} 2$ pin & 2 pin CFL $36 \mathrm{~W}$ & Fluorescent tube $18 \mathrm{~W} 2$ feet \\
\hline BA Admin & 396 & 0 & 2372 & 5136 & 93 \\
\hline $\mathrm{BB}$ & 5 & 14 & 244 & 816 & 8 \\
\hline $\mathrm{BC}$ & 2 & 10 & 404 & 888 & 4 \\
\hline $\mathrm{BD}$ & 20 & 11 & 124 & 204 & 4 \\
\hline $\mathrm{BE}$ & 46 & 18 & 296 & 924 & 4 \\
\hline $\mathrm{BF}$ & 44 & 10 & 200 & 102 & 4 \\
\hline BG & 2 & 12 & 336 & 1122 & 4 \\
\hline $\mathrm{BH}$ & 10 & 10 & 248 & 288 & 4 \\
\hline BJ & 18 & 12 & 270 & 924 & 4 \\
\hline $\mathrm{BL}$ & 56 & 0 & 51 & 2154 & 36 \\
\hline $\mathrm{BM}$ & 105 & 0 & 786 & 1929 & 38 \\
\hline $\mathrm{BN}$ & 61 & 0 & 335 & 3609 & 27 \\
\hline BV & 8 & 0 & 0 & 252 & 135 \\
\hline Food court & 108 & 12 & 0 & 0 & 0 \\
\hline COIT BW & 286 & 0 & 3212 & 4989 & 97 \\
\hline Amanah & 1933 & 0 & 605 & 0 & 1824 \\
\hline Murni & 1320 & 0 & 0 & 0 & 3698 \\
\hline Ilmu & 1893 & 0 & 612 & 0 & 1812 \\
\hline Cendekiawan & 1056 & 0 & 0 & 0 & 4752 \\
\hline Library & 1382 & 0 & 2624 & 5094 & 126 \\
\hline Total & 8751 & 109 & 12719 & 28431 & 12674 \\
\hline
\end{tabular}

TABLE 4: Energy consumption between present and alternative light per day.

\begin{tabular}{|c|c|c|c|c|c|c|}
\hline Present Light & $\begin{array}{c}\text { Fluorescent tube } \\
36 \mathrm{~W} 4 \text { feet }\end{array}$ & CFL $14 \mathrm{~W}$ & $13 \mathrm{~W} / 2$ pin & CFL $36 \mathrm{~W} / 4$ pin & $\begin{array}{c}\text { Fluorescent tube } \\
18 \mathrm{~W} 2 \text { feet }\end{array}$ & Total (kWh) \\
\hline $\mathrm{kWh}$ & $2,520.29$ & 12.21 & $1,322.78$ & $8,188.13$ & $1,825.06$ & $13,868.46$ \\
\hline Alternative light & $20 \mathrm{~W}-4 \mathrm{ft}$ LED tube & 9 W LED bulb & $8 \mathrm{~W} / 2$ pin LED & $22 \mathrm{~W} / 4$ pin LED tube & $10 \mathrm{~W}-2 \mathrm{ft}$ LED tube & Total (kWh) \\
\hline $\mathrm{kWh}$ & $1,400.16$ & 7.85 & 814.02 & $5,003.86$ & $1,013.92$ & $8,239.80$ \\
\hline
\end{tabular}

TABLE 5: Energy consumption between existing and alternative fixtures.

\begin{tabular}{lc}
\hline Year & LED energy consumption $(\mathrm{kWh})$ \\
\hline 2014 & $3,605,798.56$ \\
2015 & $3,459,453.50$ \\
2016 & $3,313,108.45$ \\
2017 & $3,166,763.39$ \\
2018 & $3,020,418.34$ \\
2019 & $2,874,073.28$ \\
2020 & $2,727,728.22$ \\
2021 & $2,581,383.17$ \\
2022 & $2,435,038.11$ \\
2023 & $2,288,693.06$ \\
2024 & $2,142,348.00$ \\
\hline
\end{tabular}

3.3. Life Cycle Analysis and Payback Period. To analyze life cycle cost of the lighting system, the total cost of installation, maintenance, and operation of its lifespan have been considered. In this project LCC is used to determine the cost of energy effective progress of LED illumination system which will be implemented. The complete LCC analysis calculation for the $20 \mathrm{~W}$ LED tube replaced with the Philips $36 \mathrm{~W}$ fluorescent tube is presented in Table 6. The same method have been used to analyze the LCC of 10 W LED tube replaced with Philips $18 \mathrm{~W}$ fluorescent tube, $22 \mathrm{~W} / 4$ pin LED light replaced with the Philips $36 \mathrm{~W} / 4$ Pin, $8 \mathrm{~W} / 2$ pin LED bulb replaced with the Philips $13 \mathrm{~W} / 2$ pin CFL, and $9 \mathrm{~W}$ LED bulb replaced with the Philips 14 W CFL bulb.

The payback period after complete retrofit for the $20 \mathrm{~W}$ LED is 4.01 years, $10 \mathrm{~W}$ LED tube is 3.86 years, $22 \mathrm{~W} / 4$ pin LED tube is 4.58 years, $8 \mathrm{~W} / 2$ pin LED is 3.48 years, and $9 \mathrm{~W}$ LED is 4.27 years. Basically after four years the selected buildings will bring profit for the investment. The result of the payback period analysis is shown in Figure 5.

3.4. Emission Reduction. Analysis on emission reduction by retrofitting energy saving LEDs is conducted by predicting the future data of fuel mixing to generate electricity in Malaysia. However, the used data might have variance with the real condition due to the uncountable reasons that are not 
TABLE 6: LCC analysis for the $20 \mathrm{~W}$ LED tube replacing Philips $36 \mathrm{~W}$ fluorescent tube.

\begin{tabular}{|c|c|c|}
\hline Variables & Value & Unit \\
\hline LED-wattage & 20 & Watts \\
\hline LED-single unit cost & RM60.00 & Ringgit \\
\hline Existing light-wattage & 36 & Watts \\
\hline Existing light-single unit cost & RM10.00 & Ringgit \\
\hline Number of lamps & 8751 & $\operatorname{Lamp}(\mathrm{s})$ \\
\hline Running time per day & 8 & Hours \\
\hline Operational days (per year) & 260 & Days \\
\hline Cost of energy/kWh & RM0.39 & Ringgit \\
\hline Calculations & Existing system & LED \\
\hline \multicolumn{3}{|l|}{ Electrical costs } \\
\hline Electrical load of lamp(s) & 315036 & 175020 \\
\hline Running time per year & 2080 & 2080 \\
\hline Energy consumed per year (kWh) & 655274.88 & 364041.6 \\
\hline Electrical demand saving (kWh) & 0 & 291233.28 \\
\hline Total cost of energy (per year) & RM257,523.03 & RM143,068.35 \\
\hline Saving the electrical fees (per year) & RM0.00 & RM114,454.68 \\
\hline \multicolumn{3}{|l|}{ Capital requirements } \\
\hline Purchase requirements Cost & RM87,510.00 & RM525,060.00 \\
\hline Installation cost per unit & RM2.00 & RM1.00 \\
\hline Installation costs & RM17,502.00 & RM8,751.00 \\
\hline Total capital investment requirements & RM105,012.00 & RM533,811.00 \\
\hline Net investment requirement & RM0.00 & RM428,799.00 \\
\hline \multicolumn{3}{|l|}{ Maintenance requirements } \\
\hline Life time of lamp (operating hours) & 15000 & 50000 \\
\hline Replacements required (per year) & 1213.47 & 364.04 \\
\hline Replacement costs (per year) & RM12,134.72 & RM21,842.50 \\
\hline Installation cost per new unit & RM2.00 & RM1.00 \\
\hline Maintenance costs (per year) & $\mathrm{RM} 2,426.94$ & RM364.04 \\
\hline Total maintenance costs (per year) & RM14,561.66 & RM22,206.54 \\
\hline Saving maintenance (per year) & RM0.00 & $-\mathrm{RM} 7,644.87$ \\
\hline \multicolumn{3}{|l|}{ ROI results } \\
\hline Total operating cost (per year) & RM272,084.69 & RM165,274.89 \\
\hline $\begin{array}{l}\text { Total savings first year } \\
\text { Saving the electrical fees + savings maintenance }\end{array}$ & RM0.00 & RM106,809.81 \\
\hline $\begin{array}{l}\text { Payback period in years } \\
\text { Time to payback capital requirement cost }\end{array}$ & $\mathrm{n} / \mathrm{a}$ & 4.01 \\
\hline LED return on investment (ROI) over 10 years & RM0.00 & RM534,287.05 \\
\hline
\end{tabular}

predictable and is out of scope of this study. The predicted fuel combination to generate electricity in Malaysia that is used in this project is presented in Figure 6. As the graph shows, Malaysia is also beginning to invest toward renewable energies.

As a result of retrofitting, the overall amount of electricity consumption decreases and consequently would help the environment by decreasing the harmful effect of the greenhouse gases. The proposed model suggests overall emission production reduction of around $3,746,433 \mathrm{~kg}$ of $\mathrm{CO}_{2}$,
$23,473 \mathrm{~kg}$ of $\mathrm{SO}_{2}, 12,585 \mathrm{~kg}$ of $\mathrm{NO}_{x}$, and $1,317 \mathrm{~kg}$ of $\mathrm{CO}$ after $100 \%$ retrofit. Graph of total reduction in gases emission of $\mathrm{CO}_{2}, \mathrm{SO}_{2}, \mathrm{NO}_{x}$, and $\mathrm{CO}$ by electricity generation from $0 \%$ to $100 \%$ retrofitting is presented in Figure 7, which shows the increment of reduction in emission every year.

\section{Conclusion}

Day by day the usage of electricity increases globally due to the ever increasing demand in the developed and developing 

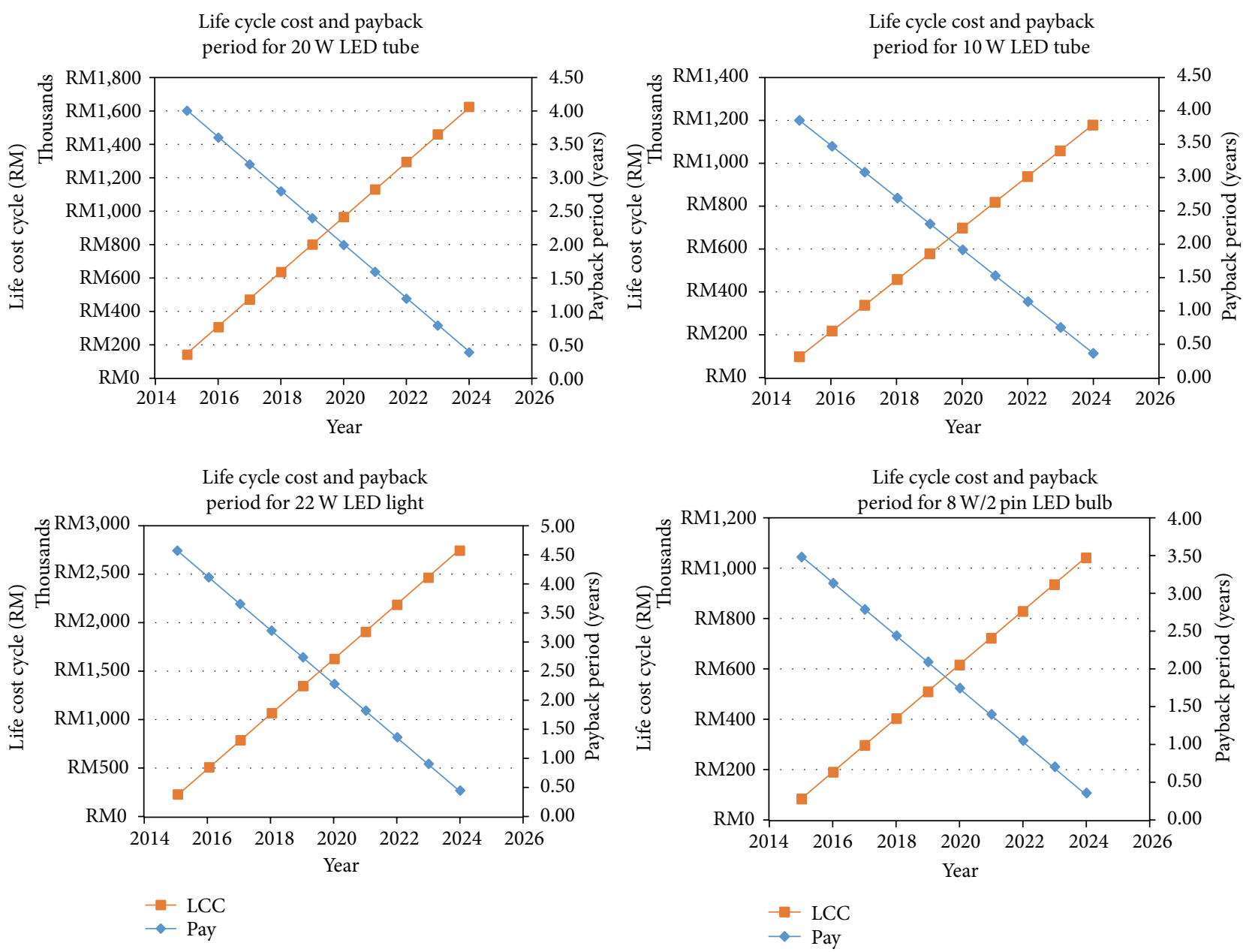

FIGURE 5: The payback period analysis.

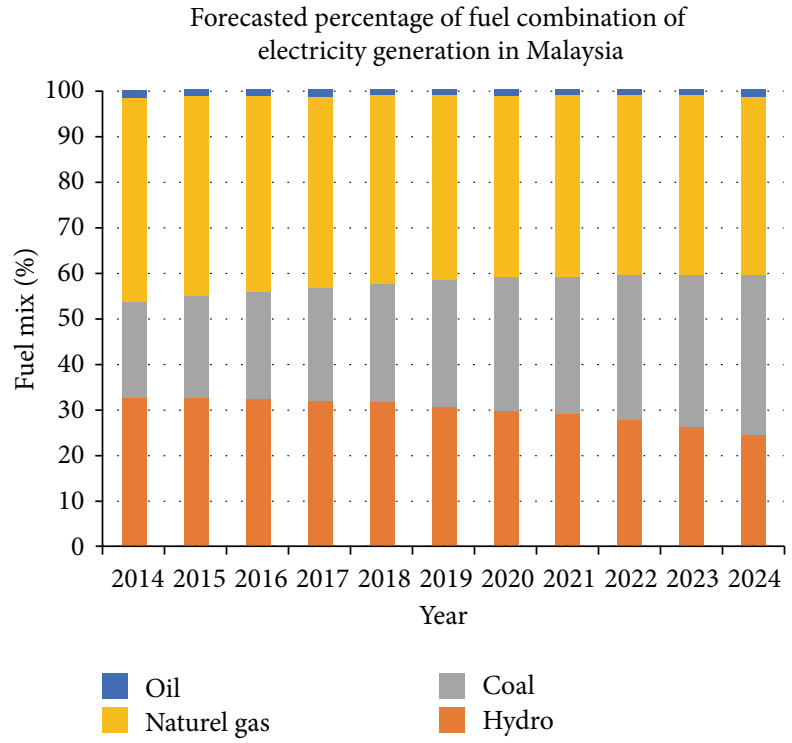

FIGURE 6: Forecasted percentage of fuel combination of electricity generation in Malaysia. countries. One of the fast options to save the energy is to use energy efficient electrical appliances among which lighting system has a great potential on saving energy. The present project has focused on the selected buildings in the Universiti Tenaga Nasional campus with the objective of designing a proper retrofit scenario and calculates the potential electricity saving, the payback period, and the potential environmental benefits. In this project, the energy saving and emission production reduction have been analyzed based on the comparison between the existing lighting system and the proposed LED retrofitting. In this survey the policy for retrofitting the old lighting system with the new energy saving LEDs starts with $10 \%$ for the first year and continues constantly for 10 years until all the lighting systems have been replaced. The result of the life cycle analysis reveals that after four years, the selected buildings will bring profit for the investment. Further comparison has been done between T5 electronic ballast and LED tube. Both T5 and LED are much more energy efficient compared to the existing CFL lighting system. By retrofitting $100 \%$ of the existing lighting system with the LED lights, around $44 \%$ saving of energy can be saved with payback period of 4.01 year. However, by using 


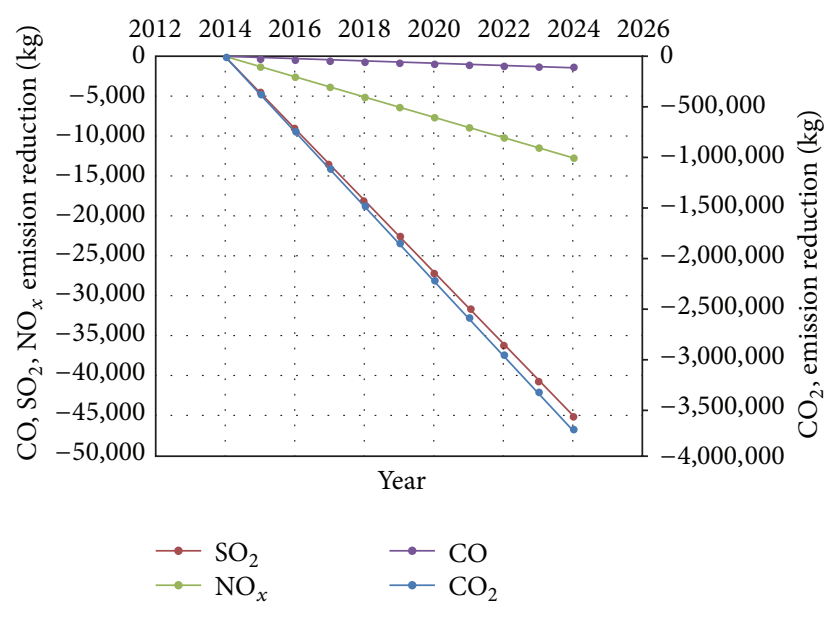

FIGURE 7: Pattern of emission reduction of $\mathrm{CO}_{2}, \mathrm{SO}_{2}, \mathrm{NO}_{x}$, and $\mathrm{CO}$ by electricity generation from $0 \%$ to $100 \%$ retrofitting.

T5 tube with electronic ballast the saving limits to $22 \%$ with payback period of 3.8 years. Although, the initial cost of LED lighting system is higher compared to T5 electronic ballast, it would bring more saving in long term.

\section{Conflict of Interests}

The authors declare that there is no conflict of interests regarding the publication of this paper.

\section{Acknowledgments}

The authors would like to acknowledge the Ministry of Higher Education of Malaysia and The University of Malaya, Kuala Lumpur, Malaysia, for the financial support under UM.C/HIR/MOHE/ENG/15 (D000015-16001) and BKP (BK032-2013).

\section{References}

[1] S. Uddin, H. Shareef, and A. Mohamed, "Power quality performance of energy-efficient low-wattage LED lamps," Measurement, vol. 46, no. 10, pp. 3783-3795, 2013.

[2] P. K. Soori and M. Vishwas, "Lighting control strategy for energy efficient office lighting system design," Energy and Buildings, vol. 66, pp. 329-337, 2013.

[3] T. M. I. Mahlia, M. F. M. Said, H. H. Masjuki, and M. R. Tamjis, "Cost-benefit analysis and emission reduction of lighting retrofits in residential sector," Energy and Buildings, vol. 37, no. 6, pp. 573-578, 2005.

[4] J. Trifunovic, J. Mikulovic, Z. Djurisic, M. Djuric, and M. Kostic, "Reductions in electricity consumption and power demand in case of the mass use of compact fluorescent lamps," Energy, vol. 34, no. 9, pp. 1355-1363, 2009.

[5] Z. Ma, P. Cooper, D. Daly, and L. Ledo, "Existing building retrofits: methodology and state-of-the-art," Energy and Buildings, vol. 55, pp. 889-902, 2012.

[6] A. H. W. Lee, "Verification of electrical energy savings for lighting retrofits using short- and long-term monitoring," Energy
Conversion and Management, vol. 41, no. 18, pp. 1999-2008, 2000.

[7] D. Caicedo, A. Pandharipande, and G. Leus, "Occupancy-based illumination control of LED lighting systems," Lighting Research and Technology, vol. 43, no. 2, pp. 217-234, 2011.

[8] S. Choi and T. Kim, "Symmetric current-balancing circuit for LED backlight with dimming," IEEE Transactions on Industrial Electronics, vol. 59, no. 4, pp. 1698-1707, 2012.

[9] Y.-C. Li and C.-L. Chen, "A novel single-stage high-powerfactor AC-to-DC LED driving circuit with leakage inductance energy recycling," IEEE Transactions on Industrial Electronics, vol. 59, no. 2, pp. 793-802, 2012.

[10] T. M. I. Mahlia, H. A. Razak, and M. A. Nursahida, "Life cycle cost analysis and payback period of lighting retrofit at the University of Malaya," Renewable and Sustainable Energy Reviews, vol. 15, no. 2, pp. 1125-1132, 2011.

[11] J. Di Stefano, "Energy efficiency and the environment: the potential for energy efficient lighting to save energy and reduce carbon dioxide emissions at Melbourne University, Australia," Energy, vol. 25, no. 9, pp. 823-839, 2000.

[12] S. Uddin, H. Shareef, A. Mohamed, M. A. Hannan, and K. Mohamed, "LEDs as energy efficient lighting systems: a detail review," in Proceedings of the IEEE Student Conference on Research and Development (SCOReD '11), pp. 468-472, December 2011.

[13] N. Chen and H. S.-H. Chung, "A driving technology for retrofit LED lamp for fluorescent lighting fixtures with electronic ballasts," IEEE Transactions on Power Electronics, vol. 26, no. 2, pp. 588-601, 2011.

[14] W. R. Ryckaert, K. A. G. Smet, I. A. A. Roelandts, M. van Gils, and P. Hanselaer, "Linear LED tubes versus fluorescent lamps: an evaluation," Energy and Buildings, vol. 49, pp. 429-436, 2012.

[15] F. P. Vahl, L. M. S. Campos, and N. Casarotto Filho, "Sustainability constraints in techno-economic analysis of general lighting retrofits," Energ Buildings, vol. 67, pp. 500-507, 2013.

[16] T. M. I. Mahlia, "Emissions from electricity generation in Malaysia," Renewable Energy, vol. 27, no. 2, pp. 293-300, 2002.

[17] Z. Pei-Dong, J. Guomei, and W. Gang, "Contribution to emission reduction of $\mathrm{CO}_{2}$ and $\mathrm{SO}_{2}$ by household biogas construction in rural China," Renewable and Sustainable Energy Reviews, vol. 11, no. 8, pp. 1903-1912, 2007.

[18] E. Mahalingam, New Green Rating Tools to Boost Value of Old Buildings, The Star, Kuala Lumpur, Malaysia, 2010.

[19] H. Heisler, Advanced Engine Technology, SAE International, Warrendale, Pa, USA, 1995.

[20] A. J. Johnson and G. H. Auth, Fuels and Combustion Handbook, McGraw-Hill, New York, NY, USA, 1st edition, 1951.

[21] F. J. Wallace and W. A. Linning, Basic Engineering Thermodynamics: S.I. Units, Pitman, London, UK, 1st edition, 1970.

[22] A. Mazandarani, T. M. I. Mahlia, W. T. Chong, and M. Moghavvemi, "A review on the pattern of electricity generation and emission in Iran from 1967 to 2008," Renewable and Sustainable Energy Reviews, vol. 14, no. 7, pp. 1814-1829, 2010.

[23] M. Shekarchian, M. Moghavvemi, B. Rismanchi, T. M. I. Mahlia, and T. Olofsson, "The cost benefit analysis and potential emission reduction evaluation of applying wall insulation for buildings in Malaysia," Renewable and Sustainable Energy Reviews, vol. 16, no. 7, pp. 4708-4718, 2012.

[24] M. Shekarchian, M. Moghavvemi, T. M. I. Mahlia, and A. Mazandarani, "A review on the pattern of electricity generation and emission in Malaysia from 1976 to 2008," Renewable \& Sustainable Energy Reviews, vol. 15, no. 6, pp. 2629-2642, 2011. 
[25] P S. The Art of the Long View: Planning in an Uncertain World, Doubleday, New York, NY, USA, 1996.

[26] A. Mazandarani, T. M. I. Mahlia, W. T. Chong, and M. Moghavvemi, "Fuel consumption and emission prediction by Iranian power plants until 2025," Renewable and Sustainable Energy Reviews, vol. 15, no. 3, pp. 1575-1592, 2011.

[27] Tenaga Nasional Sdn Bhd, Increase in Electricity Tariff, 2013. 


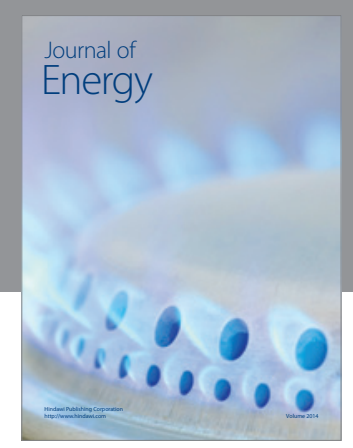

Journal of

Industrial Engineering
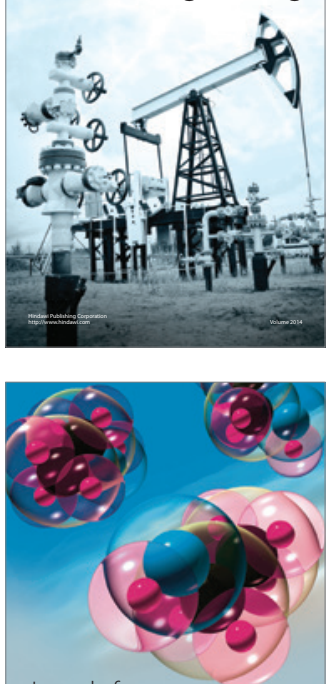

Fuels
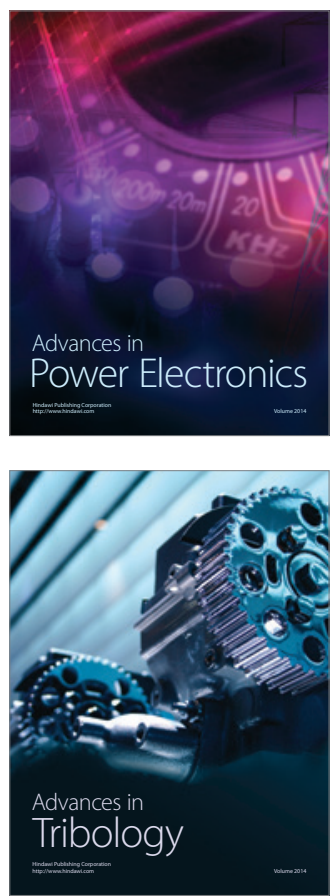

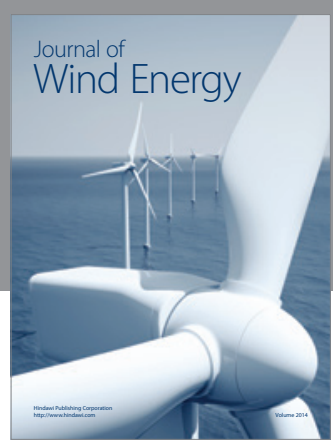

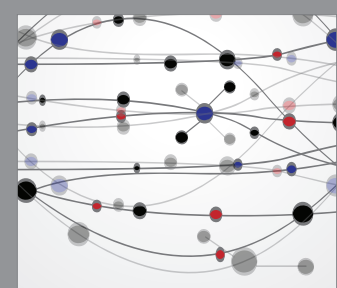

The Scientific World Journal

Submit your manuscripts at http://www.hindawi.com

Journal of

Structures
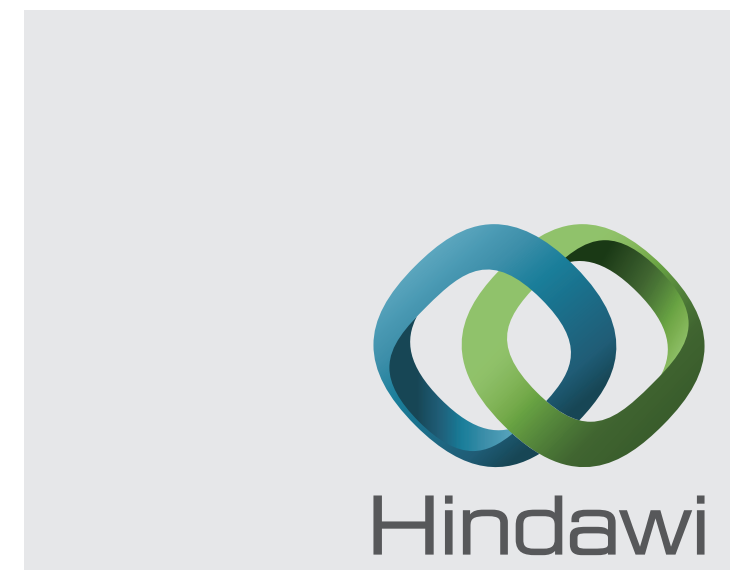

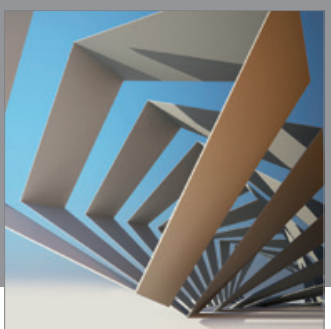

Rotating

Machinery
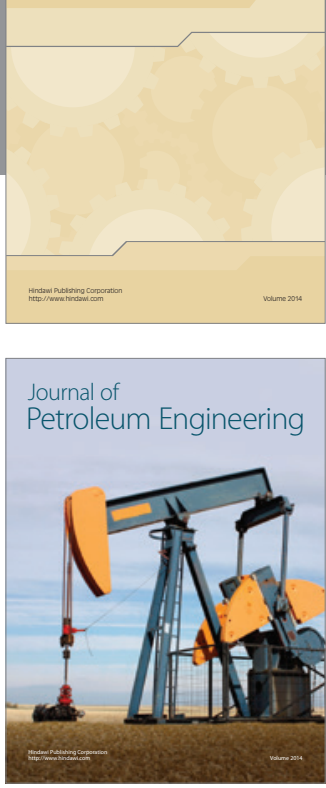

Journal of

Solar Energy
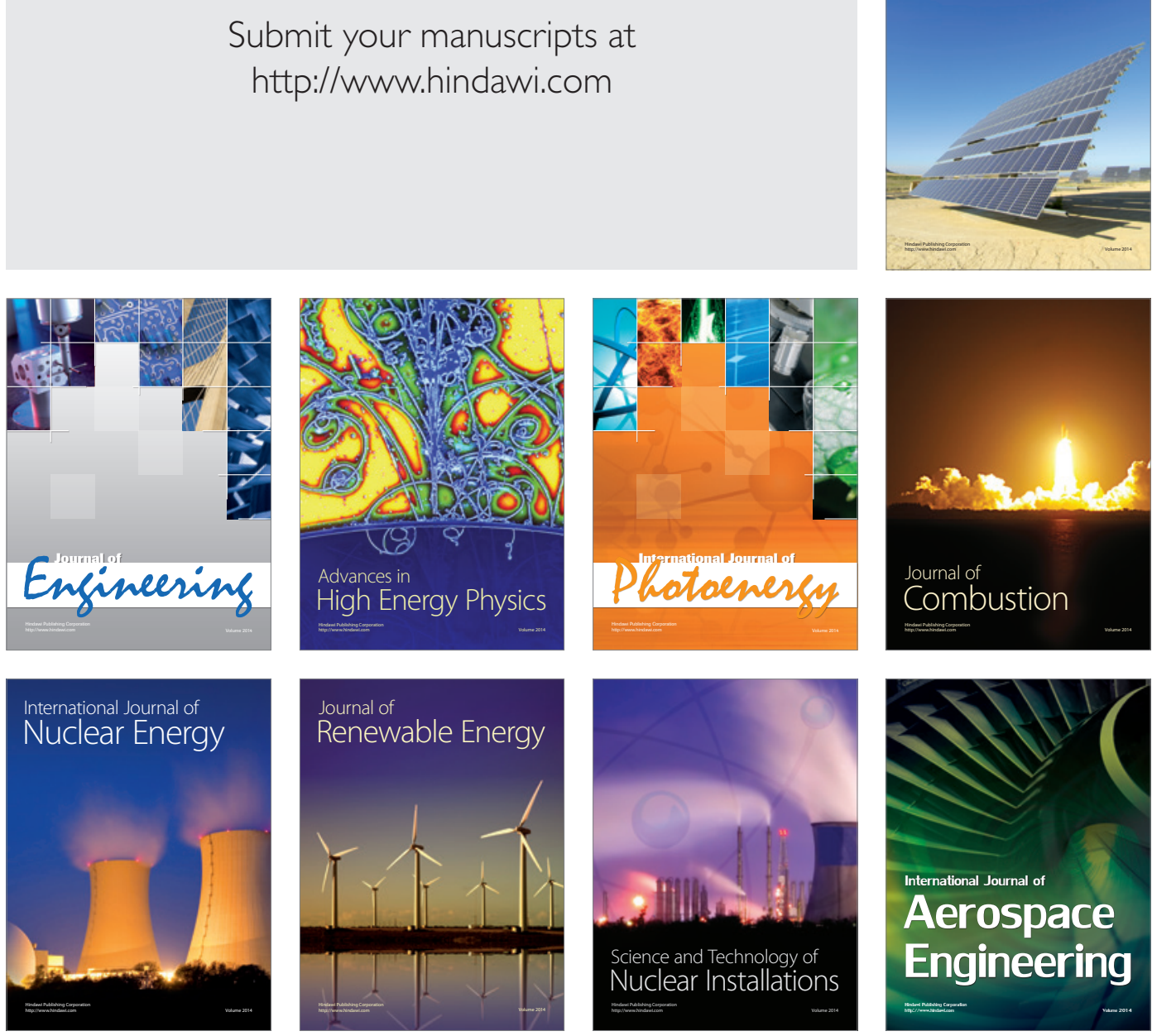